\title{
Fatores que interferem no (não) credenciamento de pesquisadores em programas de pós-graduação: um estudo nas universidades públicas em Goiás
}

\author{
Itala Moreira Alves \\ Bibliotecária; Universidade Federal de Goiás; \\ italaalves0@gmail.com \\ João de Melo Maricato \\ Doutor; Universidade Federal de Goiás; \\ jmmaricato@gmail.com \\ Dalton Lopes Martins \\ Doutor; Universidade Federal de Goiás: \\ dmartins@gmail.com
}

\begin{abstract}
Resumo: Programas de pós-graduação stricto sensu são importantes para a formação de pesquisadores, para a produção e difusão de conhecimentos e desenvolvimento de tecnologias. Este trabalho visa levantar fatores que levam pesquisadores a se credenciarem (ou não) em programas dessa natureza, mesmo reunindo certas condições para tal. A metodologia utilizada consistiu na aplicação de um questionário a 578 docentes das instituições públicas de ensino superior do Estado de Goiás (UFG, UEG, IFGoiano e IFGoiás) que possuíam ao menos um artigo científico publicado nos últimos 5 anos (2009 à 2014). Ao total, 122 docentes (21\%) responderam os questionários. Observou-se que $94 \%$ dos entrevistados têm interesse em participar de programas de pós-graduação stricto sensu. Os fatores organizacionais são os que mais influenciam os pesquisadores a não se credenciar em programas de pós-graduação, no entanto, os fatores relacionados ao trabalho, à organização a ao pessoal combinados entre si parecem exercer influência nesta decisão.
\end{abstract}

Palavras-chave: Pós-graduação. Docente. Comportamento organizacional. Goiás. Universidades públicas.

\section{Introdução}

Desenvolver novos conhecimentos, aplicar novas tecnologias, solucionar problemas sociais e do meio ambiente, investigar formas de melhorar a qualidade de vida da população, aumentar a produtividade, dentre tantas outras demandas, são temas 
relevantes para a agenda científica e estão intimamente condicionados ao desenvolvimento de recursos humanos qualificados.

No Brasil, a pesquisa está fortemente ligada à universidade e ao seu sistema de pós-graduação, assumindo um papel importante para a formação de pesquisadores e produção de conhecimentos e tecnologias. Dessa forma, o desenvolvimento de programas de pós-graduação em instituições de ensino superior é fundamental para a melhoria das competências científicas e tecnológicas nacionais e regionais.

Diante da potencialidade dos cursos de pós-graduação para o desenvolvimento da ciência, tecnologia e inovação, o sistema é um objeto de análise que merece ser mais bem compreendido. Os recursos humanos, constituído especialmente por professores e pesquisadores e seus variáveis níveis de interesses e motivações para decidirem ou não atuar em programas de pós-graduação são diversos: organizacionais, sociológicos, econômicos, comportamentais, ideológicos, culturais, de saúde, etc. Por isso, atualmente, os fatores que interferem na decisão de professores e pesquisadores em atuar (ou não) em programas de pós-graduação não são claros.

A presente pesquisa visa levantar fatores que levam pesquisadores a decidirem por se credenciar ou não em programas de pós-graduação stricto sensu, mesmo que reúnam certas condições para tal. Para compreender melhor essa questão são estudados temas como: a pós-graduação no Brasil; os critérios de avaliação utilizados pela Coordenação de Aperfeiçoamento de Pessoal de Nível Superior (Capes) para credenciamento do docente em programas de pós-graduação; críticas ao sistema de avaliação da Capes; e teorias relacionadas à motivação e comportamento organizacional de docentes. Esse levantamento tem o intuito de identificar possíveis fatores que possam estar interferindo na decisão de pesquisadores a não atuarem em programas de pós-graduação.

As universidades devem buscar meios para aperfeiçoar seus sistemas de pósgraduação com os recursos (humanos e materiais) que possuem. Logo, considera-se fundamental que haja esforços de planejamento e monitoramento informacional para que se compreendam determinados sistemas locais e regionais de pós-graduação. Entende-se, neste contexto, que a visão dos professores/pesquisadores pode auxiliar no planejamento de políticas públicas mais eficientes e eficazes em ciência, tecnologia e inovação. 
A presente pesquisa mantém proximidade aos estudos sociais da ciência, aos estudos bibliométricos e cientométricos e, também, aos estudos de comportamento organizacional. Diante do exposto, a presente pesquisa objetiva levantar fatores que influenciem na decisão por parte de professores/pesquisadores de credenciamento ou não credenciamento em programas de pós-graduação stricto sensu, mesmo reunindo certas condições para tal. Para isso, são analisados, como corpus empírico de análise, os professores doutores das universidades públicas o estado de Goiás que publicaram ao menos um artigo científico no período de 2009 a 2014, mas que não estão credenciados em programas de pós-graduação.

\section{Pós-graduação brasileira: desenvolvimento e disparidades regionais}

Após a Segunda Guerra Mundial houve um avanço tecnológico que acelerou a automação nos mais diversos setores econômicos, desencadeando transformações na estrutura social e levando o ensino superior a se organizar em disciplinas direcionadas para profissões mais especializadas, valorizando a educação como um requisito para o mercado de trabalho.

Segundo Simões (2003, p. 35) na década de 50, a demanda por profissionais especializados era muito maior do que a oferta; no entanto, a força de trabalho era composta de mão-de-obra agrária com um grau de escolaridade muito baixo, comprometendo a produtividade. Assim, entendeu-se que a solução era investir na expansão do ensino superior, evidenciando-se que os cursos de graduação já não poderiam atender as necessidades do progresso, favorecendo o surgimento e consolidação de um novo nível de ensino: o da pós-graduação (SIMÕES, 2003).

No Brasil, as razões que levaram a criação da pós-graduação foram duas: a constatação da carência de pessoal altamente qualificado para gerir projetos de desenvolvimento do país e a necessidade de qualificar o corpo docente exigido pela grande expansão que se verificava no ensino superior. Além disso, ela foi patrocinada, em suas origens, por dois setores da tecnocracia governamental: o da área econômica e o da área educacional (HAMBURGER, $1980^{1}$ apud SGUISSARDI, 2006).

Ressalta-se que a concepção de pós-graduação no país está integrada à ideia de pesquisa desde o seu surgimento. Em 1964, as principais características da pósgraduação brasileira foram fixadas pelo Parecer 977, conhecido como "Parecer 
Sucupira" e aprovado pelo Conselho Federal de Educação (DANTAS, 2004). Esse parecer estabeleceu, pela primeira vez, o formato institucional básico da pósgraduação brasileira, definindo dois níveis de formação: a pós-graduação stricto sensu (PGSS), que engloba os cursos de mestrado e doutorado e a pós-graduação lato sensu (PGLS), que inclui os cursos de especialização e aperfeiçoamento (BALBACHEVSKY, 2005).

Somente com a reforma de 1968 os estudos pós-graduados adquiriram novas características, observando-se, a partir do ano de 1970, um salto de qualidade, passando a serem privilegiados nas políticas de apoio ao desenvolvimento científico e tecnológico. Em 1975, o Conselho Nacional de Pesquisa foi reformado e transformado no Conselho Nacional de Desenvolvimento Científico e Tecnológico (CNPq). Em 1976, a Coordenação de Aperfeiçoamento de Pessoal de Nível Superior (Capes) organizou o primeiro processo de avaliação dos programas de pós-graduação, centrando sua avaliação na produção científica dos pesquisadores ligados a cada programa (BALBACHEVSKY, 2005).

Com o surgimento e aperfeiçoamento dessas organizações, especialmente o CNPq e a Capes, observou-se a institucionalização da Política Científica e Tecnológica no Brasil. Desde esse momento, os programas de pós-graduação passaram a receber apoio dessas e de outras agências de fomento como a Financiadora de Estudos e Projetos (Finep) e as Fundações Estaduais de Amparo à Pesquisa (FAPs).

No entanto, a distribuição de recursos entre as universidades brasileiras e regiões ocorreu historicamente de maneira desigual: foram criados ambientes mais favoráveis que atraíam os melhores pesquisadores em determinadas regiões em detrimento de outras, provocando uma estratificação nos programas de pós-graduação nas diversas instituições de ensino. Isso fez com que uma grande quantidade de instituições públicas não conseguisse (e ainda não consegue) desenvolver uma pósgraduação forte e extensa. Dantas (2004) reforça que o Brasil é um país continental, com grande diversidade de instituições e programas recomendados de pós-graduação, porém, sediados em regiões de maneira desigual.

Cabral Neto e Castro (2013) afirmam que nos últimos anos pode ser observado um crescimento da pós-graduação no Brasil como um todo, entretanto, esse 
crescimento não se dá de forma homogênea, havendo concentração de cursos na região sudeste $(66,8 \%)$.

Observando os dados de distribuição dos programas de pós-graduação no Brasil disponibilizado pelo Sistema de Gerenciamento Geográfico da Capes (Geocapes) (CAPES, 2013), constata-se que o estado de Goiás, em 2012, contava com 45 cursos de mestrado, 3 de doutorado, 20 de mestrado/doutorado e 6 de mestrado profissional, totalizando 74 cursos de pós-graduação. Assim, o estado ocupava o décimo terceiro lugar em relação ao país, estando atrás de estados que até então tinham pouca representatividade nesse âmbito como Pará, Paraíba e Ceará. Ainda assim, a região sudeste permanece dominante no cenário nacional, contando com 1562 programas de pós-graduação.

Comparado com o sistema de pós-graduação nacional, o Estado de Goiás tem um sistema relativamente inexpressivo. O Estado carece, em linhas gerais, de pessoal qualificado em nível de pós-graduação para impulsionar o desenvolvimento científico, tecnológico e de inovação, não apresenta condições de atender os desafios de produção de conhecimentos demandados pelas empresas e organizações do Estado, dificultando seu desenvolvimento econômico e social.

\section{0 sistema de avaliação de programas de pós-graduação na Capes}

No Brasil, a Capes é umas das organizações responsáveis pelo financiamento da pósgraduação e a responsável pela avaliação dos programas de mestrado e doutorado. A agência possui um sistema de avaliação desenvolvido há décadas que tem sido eficiente na expansão e consolidação da pós-graduação stricto sensu no país. Apesar disso, o sistema Capes de avaliação é alvo constante de críticas.

Segundo Maccari, Lima e Riccio (2009), os objetivos que justificam inicialmente a concepção e adoção de programas de avaliação dos cursos de pósgraduação podem ser assim resumidos: a) facilitar a distribuição de bolsas de estudo para mestrandos e doutorandos e orientar o investimento das agências federais na formação de recursos humanos de alto nível; (b) subsidiar a política educacional relativa à pós-graduação e à universidade, assim como suas relações com a educação básica; (c) criar um sistema permanente de informações sobre a pós-graduação brasileira; (d) regular a expansão da pós-graduação, recomendando o apoio aos cursos Fatores que interferem no (não) credenciamento de pesquisadores em programas de pós- $\mid 154$ graduação: um estudo nas universidades públicas em Goiás 
novos e incorporando-os progressivamente ao sistema de avaliação e acompanhamento; (e) credenciar esses cursos, tornando válidos, em plano nacional, os certificados por eles expedidos.

Desta forma, atualmente, as atividades dessa instituição podem ser agrupadas nas seguintes linhas de ação: avaliação da pós-graduação stricto sensu; acesso e divulgação da produção científica; investimentos na formação de recursos de alto nível no país e no exterior; promoção da cooperação científica internacional e indução e fomento da formação inicial e continuada de professores para a educação básica nos formatos presencial e a distância (CAPES, 2014).

O sistema de avaliação da Capes é dividido em dois processos que se referem à (1) entrada e (2) à permanência dos cursos (mestrado profissional ou acadêmico e doutorado) no Sistema Nacional de pós-graduação. Esses cursos são enquadrados em 48 áreas de avaliação, seguindo uma mesma sistemática e um mesmo conjunto de quesitos básicos estabelecidos no Conselho Técnico Científico da Educação SuperiorCTC-ES (CAPES, 2014). A Portaria n 193, de 4 de outubro de 2011, é o documento que apresenta as normas e procedimentos para a apresentação e validação de propostas de cursos novos de pós-graduação stricto sensu (Mestrado e Doutorado) (BRASIL, 2011).

Para os processos avaliativos, tanto na elaboração e submissão de propostas de cursos novos quanto na avaliação dos cursos em funcionamento, têm-se como referência os documentos de área. Nesses estão descritos o estado atual, as características e as perspectivas, assim como os quesitos considerados prioritários na avaliação dos programas de pós-graduação pertencentes a cada uma das 48 áreas de avaliação. Em conjunto com as fichas de avaliação e os relatórios de avaliação, os documentos de área constituem o trinômio que expressa os processos e os resultados da avaliação dos cursos em funcionamento (CAPES, 2014).

Observando-se os documentos de área, constata-se que os principais critérios de avaliação relacionam-se: à proposta do programa; ao corpo docente; às atividades de pesquisa; às atividades de formação; ao corpo discente; à quantidade de teses e dissertações e à produção intelectual. A produção científica publicada em periódicos qualificados é um quesito com grande peso na avaliação. 
Em última instância, os recursos humanos (professores/pesquisadores doutores) podem ser considerados o cerne da avaliação. Salienta-se que no quesito Recursos humanos, o sistema de avaliação vigente valoriza aspectos ligados à qualificação do corpo docente como orientações programáticas, carga horária e volume/qualidade das publicações (DANTAS, 2004). Maccari, Lima e Riccio (2009) destacam que o "corpo docente" representa $20 \%$ no peso total da avaliação, mas, apesar deste percentual, esse critério pode ser considerado o mais importante, uma vez que tem o poder de influenciar diretamente os resultados dos demais critérios da avaliação como:

Formação dos docentes permanentes; Adequação da dimensão, composição e dedicação dos docentes permanentes; Perfil do corpo permanente em relação à proposta do programa; Atividade docente permanente na pós-graduação; Atividade docente permanente na graduação; Participação dos docentes em pesquisa e desenvolvimento de projetos. (MACCARI; LIMA; RICCIO, 2009, p. 81-82).

Para Moro et al. (2013, p. 609), os programas de pós-graduação exigem dos professores produção e publicações com a finalidade de atender as metas estabelecidas pelo sistema de avaliação Capes. Eles, ainda, desempenham várias funções dentro da instituição como a docência, a pesquisa, a extensão e a gestão, estando em contato direto com alunos, servidores e colegas. Desse modo, conduzem ao mesmo tempo o processo de ensino em sala de aula, a orientação de grupos de trabalho, além de fazer o papel de líderes na organização, sendo necessário conhecer, desenvolver e praticar conceitos e técnicas de motivação e satisfação. Esses aspectos remetem à possível sobrecarga de trabalho a que o professor/pesquisador estaria submetido, podendo influenciar na sua decisão de não participação em programas de pós-graduação.

Em relação ao tempo, de acordo com a Portaria $n^{\circ}$ 1, de 4 de janeiro de 2012, os docentes permanentes, devem ter, majoritariamente, regime de dedicação integral à instituição - caracterizado pela prestação de quarenta horas semanais de trabalho admitindo-se que parte não majoritária desses docentes tenha regime de dedicação parcial (BRASIL, 2012). Além do fato de que há uma corrida em submeter os resultados dos trabalhos de pesquisa para garantir que o programa ao qual o docente 
do curso stricto sensu pertence, no mínimo, permaneça com o mesmo conceito perante a Capes ou, quem sabe, aumente o conceito (CASSANDRE, 2011).

Porém, esses critérios de avaliação não têm a aprovação de todos os pesquisadores já que alguns levantam algumas observações a respeito do Sistema de Avaliação da Capes.

Gatti et al. (2003) comentam que o modelo atual está baseado fundamentalmente na avaliação externa e centrada nos produtos, defendendo que deveria haver mais flexibilidade no modelo. Consideram, por exemplo, que cursos consolidados, cursos em reestruturação e cursos novos não podem ser tratados da mesma forma e que deveria haver maior peso na relação pós-graduação/graduação.

Hortale (2003) ressalta que os principais indicadores do instrumento de avaliação são de natureza quantitativa, faltando, assim, mais indicadores de natureza qualitativa. Em suas pesquisas, ele observou que o sistema de avaliação da Capes está mais orientado para a pesquisa do que para a qualidade do ensino.

Silva (2007) afirma que as bases fundamentais de um programa se resumem em: prestígio à linha de pesquisa e, excepcionalmente, os projetos isolados; o pesquisador e o orientando serem os sujeitos da ação, sendo que deve haver uma relação estreita entre os dois; a pesquisa clínica e experimental ser o objeto indispensável à aprovação e à classificação dos programas e; a necessidade de divulgar os resultados, mesmo antes da apresentação de tese para defesa, se possível. Assim, esse autor coloca que a questão da formação de pessoal qualificado não está sendo valorizada. No seu ponto de vista, além de preparar o pesquisador no laboratório, há que qualificá-lo também como docente e com formação humanística. Mas, nas orientações da Capes "Não se cobra por isto. O que se ouve é linha de pesquisa, publicação de resultados e em revista de impacto". (SILVA, 2007, p. 360). Ou seja, é comum a visão de que existe uma cobrança demasiada pela produtividade.

Sguissardi (2006) questiona alguns pontos em relação à avaliação Capes como: o modelo avalia a qualidade com base na quantidade dos recursos de entrada (recursos humanos, principalmente) e produção de saída (produção científica, sobretudo); a padronização do modelo é questionável diante da heterogeneidade das áreas do conhecimento e das instituições em relação a recursos e ambiente econômico regional; a ausência de critérios como gastos em pesquisa, infraestrutura e impacto Fatores que interferem no (não) credenciamento de pesquisadores em programas de pós- $\mid 157$ graduação: um estudo nas universidades públicas em Goiás Itala Moreira Alves, João de Melo Maricato e Dalton Lopes Martins 
no mercado de trabalho; o número excessivo de indicadores quantitativos e a falta de indicadores qualitativos e a diferença na valorização do trabalho docente (ensino) versus a valorização do pesquisador.

Como exposto até agora, percebe-se que a Política em Ciência e Tecnologia Brasileira promovida pela Capes está centrada na produtividade, tanto do agente pesquisador quanto do programa institucional de pesquisa em que este se insere. Além disso, identifica-se um esforço do pesquisador para produzir segundo as exigências institucionais vigentes, sacrificando muitas das vezes sua vida pessoal (LUZ, 2005).

É importante explicar que as atividades de pesquisa no Brasil (e em muitos outros países) são, substancialmente, financiadas pelo Estado por meio das agências de fomento. Observa-se que essas, se concentram nos programas de pós-graduação das universidades públicas, sendo o principal ator do processo os professores/pesquisadores. Por meio dos editais, o governo conduz (ou induz), de acordo com os variáveis interesses da política governamental, não apenas o que pesquisar, mas, também, como pesquisar, e a lista de produtos que devem resultar do processo da pesquisa (LUZ, 2005).

Luz (2005) traz reflexões relevantes que merecem ser observadas no contexto do sistema de avaliação e produção da ciência em que os professores/pesquisadores e os programas de pós-graduação estão inseridos. Essas, podem afetar na decisão de pesquisadores participarem ou não em programas de pós-graduação:

\footnotetext{
Sem consideração do real mérito ou relevância de seus "produtos", a classificação resultante do dogma acaba tendo profundas repercussões políticas e conseqüências de natureza psicossocial sobre os atores e seus nichos acadêmicos de inserção, pois dela resultam freqüentemente desqualificações de pesquisadores e de programas de pós-graduação. Inútil reafirmar aqui o grau de estresse no trabalho e o sofrimento psíquico implicados nesse processo, tanto para docentes pesquisadores como para dirigentes de programas. Mas é muito importante sublinhar o movimento de competição desenfreada para "subida de conceito" que o processo desencadeia em nível individual e institucional, com evidente conseqüência para a saúde de todos os implicados, visível em somatizações de todos os tipos, face ao agravamento do ambiente de isolamento e hostilidade no trabalho provocado pelos valores individualistas (LUZ, 2004² apud LUZ, 2005). Ambiente que não facilita em nada o intercâmbio, o compartilhamento de informações e a socialização de métodos e resultados que em princípio caracterizariam as regras do jogo da produção científica. (LUZ, 2005, p. 46-47).
} 
Cassandre (2011) elaborou uma pesquisa buscando elencar elementos para se conhecer a saúde física e mental dos docentes de duas Universidades do Paraná, comparando com os conceitos dos cursos e as áreas de atuação dos mesmos. Ao final da pesquisa, a autora destaca que a busca pelo prazer, pela satisfação e, por fim, pelo reconhecimento dos docentes também se realiza por meio do trabalho. Os docentes são estimulados e movidos por motivos subjetivos e não apenas pela lógica técnica e racional de produção que as universidades estão incorporadas.

Diante do exposto, há que se reconhecer, por um lado, que a Capes, ao longo das últimas décadas, desenvolveu um sofisticado sistema de avaliação de pósgraduação. Com isso, o sistema ampliou-se de modo significativo, qualitativamente e quantitativamente, atingindo níveis inegáveis de excelência e reconhecimento internacional. No entanto, como não existe sistema de avaliação isento de críticas e falhas, o sistema de avaliação Capes não é exceção e tem recebido duras críticas. Perante os discursos, entende-se que, de uma forma ou de outra, o sistema de avaliação Capes pode interferir na decisão de um professor/pesquisador não participar como membro de um programa de pós-graduação.

A partir dessa análise da literatura, foi possível identificar diversos fatores que se entendeu poder interferir na decisão de um pesquisador em credenciar-se ou não em um programa de pós-graduação. Esses fatores serviram como base para a elaboração do instrumento de coleta de dados e para a discussão dos resultados.

\section{Comportamentos em instituições de ensino superior}

O corpo docente/pesquisador pode ser considerado o cerne de um programa de pósgraduação, tendo um papel importante no cumprimento dos objetivos de uma instituição de ensino superior. A centralidade do papel docente faz dele um escultor fundamental da cultura institucional (MACHADO et al., 2011). Desta forma, conhecer o comportamento dos docentes torna-se necessário para compreender os fatores que afetam na sua decisão de atuar ou não em programas de pós-graduação.

Os conceitos de necessidades, motivação e satisfação têm sido bastante utilizados para explicar o comportamento humano nas organizações (RIZZATTI, 2002, p. 77). De forma ampla, pode-se dizer que este comportamento humano é imprevisível. Por isso, é utópico querer compreender todo o comportamento humano quando se leva em conta o número de variáveis envolvidas em determinada situação 
e as inúmeras maneiras pelas quais essas variáveis podem se combinar (BERGAMINI, 2011, p. 26-27). Não é o foco desta pesquisa esgotar as variáveis e fatores que podem ser levados em consideração para estudar a motivação e a satisfação dos sujeitos.

Considerando o comportamento humano em situações motivacionais, o termo "motivação" é geralmente empregado como sinônimo de forças psicológicas, desejos, impulsos, instintos, necessidades, vontades, intenção, isto é, tudo aquilo que em um indivíduo responde pelo seu dinamismo, no qual certa força impele as pessoas a agir, seja no sentido de buscar, ou de fugir de determinadas situações. (BERGAMINI, 2011).

Levy-Leboyer (1974³ , p. 150 apud BERGAMINI, 2011, p. 146) caracteriza o comportamento motivacional dentro do contexto organizacional como um fenômeno complexo, que não se pode analisar sem levar em consideração o conjunto da situação: o indivíduo (suas características e experiências) o trabalho (sua natureza e restrições); e a organização com suas regras e seus objetivos.

A literatura mostra que a satisfação no trabalho está intimamente associada à motivação dos trabalhadores. A satisfação tem sido associada a resultados organizacionais positivos, tais como maior inovação, menor stress, maior produtividade, crescimento organizacional, baixos níveis de absentismo, elevados níveis de motivação, e, também, tem sido relacionada com a satisfação com a vida (MACHADO et al., 2011).

Há vários estudos que abordam a motivação no trabalho, conforme destacado por Machado et al. (2011):

Latham e Ernst (2006) ${ }^{4}$ argumentam que a motivação no trabalho é um conjunto de forças energéticas que têm origem tanto no indivíduo como fora deste. Vallerand e outros $(1992)^{5}$ definem a motivação como o "porquê" do comportamento. A motivação está relacionada com a questão de como diferentes factores influenciam o comportamento e a produtividade. Blackburn e Lawrence $(1995)^{6}$, referem que estes factores (que afectam o comportamento e a produtividade dos docentes) são propriedades dos indivíduos (características dos docentes, nomeadamente, características sócio-demográficas ou a sua capacidade para ir ao encontro das expectativas relativas ao seu desempenho) e o ambiente de trabalho destes indivíduos (localização geográfica, sistema de regulamentação, qualidade da biblioteca ou do laboratório, entre outros factores que são características objectivas do ambiente de trabalho). (MACHADO et al., 2011, p. 174). 
Machado et al. (2011) sintetizam as teorias da motivação em quatro categorias gerais: teoria de conteúdo, de processo, de modelos situacionais e teorias de papel:

As teorias de conteúdo abordam a satisfação das necessidades e a realização de factores intrínsecos e extrínsecos (Maslow, 19707\% Alderfer, $1972^{8}$ e Herzberg, $1966^{9}$ ). As teorias de processo tentam identificar as relações entre as variáveis que compõem a motivação e as acções subsequentes usadas para influenciar o comportamento (Vroom, $1964^{10} \mathrm{e}$ Adams, $1965^{11}$ ). Os modelos situacionais examinam a interacção entre o indivíduo, a tarefa e as características organizacionais (Quarstein, McAfee e Glassman, 1992 ${ }^{12}$; Glisson e Durick, 1988 ${ }^{13}$ ). As teorias de papel analisam a interacção de papéis, posições e características individuais, e são mais conhecidas pelas duas teorias de Biddle do conflito de papéis e da ambiguidade de papéis (Goff, 2004 ${ }^{14}$ ). Mullins $(1999)^{15}$ considera quatro denominadores comuns das teorias que caracterizam a motivação: 1) um fenómeno individual, 2) um fenómeno intencional e sob o controlo do indivíduo, 3) um fenómeno multifacetado, envolvendo o entusiasmo de agir e a escolha do comportamento, e 4) um fenómeno destinado a prever o comportamento. (MACHADO et al., 2011).

Nesta pesquisa, são apresentados, brevemente, alguns modelos de estudo da motivação e da satisfação no trabalho segundo as teorias de conteúdo, passando pela Teoria de Herzberg (1966), modelos sobre satisfação de Nyquist, Hitchcock e Teherani (2000) ${ }^{16}$ e de Hagedorn $(2000)^{17}$, a partir do estudo elaborado por Machado et al. (2011).

Herzberg (1966 ${ }^{18}$ apud MACHADO et al., 2011) distingue fatores motivacionais ou fatores intrínsecos (realização, reconhecimento, o próprio trabalho, responsabilidade, progresso, crescimento) de fatores higiênicos ou fatores extrínsecos (política da empresa/instituição, supervisão, relacionamento com a direção, condições de trabalho, salário, relacionamento com os pares).

Entretanto, existe uma evidência de que a satisfação no trabalho é importante na revitalização da motivação do pessoal e em manter vivo o seu entusiasmo. No entanto, há diversos fatores que minam o empenho dos acadêmicos relativamente às suas instituições e carreiras (HAGEDORN, $2000^{19}$ apud MACHADO et al., 2011).

Nyquist, Hitchcock e Teherani e Hagedorn $\left(2000^{20}\right.$ apud MACHADO et al., 2001), apresentam um modelo de satisfação do pessoal docente em seu trabalho, sugerindo que os fatores organizacionais, os fatores relacionados com o trabalho e os fatores pessoais afetam o autoconhecimento, o conhecimento social e a satisfação. 
Os fatores organizacionais são os recursos disponíveis; as relações entre colegas; a percepção de oportunidades de promoção e progressão na carreira; a adequação da tutoria; a capacidade de tomada de decisão e o comprometimento com a organização. Os fatores relacionados com o trabalho integram a autonomia e a liberdade acadêmica, funções a desempenhar claras e coerentes, a estabilidade no emprego, o estímulo proporcionado pelo trabalho, o volume de trabalho, a remuneração, os recursos disponíveis e as pressões de tempo. Os fatores pessoais são as percepções de conflito de papéis e a interferência das responsabilidades profissionais com as responsabilidades familiares (MACHADO et al., 2011).

Hagedorn $\left(2000^{21}\right.$ apud MACHADO et al., 2011) apresenta outro modelo sobre a satisfação no trabalho dos docentes. Utiliza o Conceptual Framework of Faculty Job Satisfaction, com o objetivo de ordenar e classificar os fatores que contribuem para a satisfação no trabalho. O modelo utilizado pelo autor sugere dois conjuntos de fatores que têm impacto na satisfação no trabalho: os catalisadores e os mediadores. Um catalisador é um evento significativo da vida que pode estar ou não relacionado com o trabalho. Um mediador é uma variável ou uma situação que influencia ou modera as relações entre outras variáveis ou situações, produzindo um efeito de interação. Os mediadores representam situações, acontecimentos e circunstâncias atenuantes que fornecem o contexto em que a satisfação no trabalho deve ser considerada.

Esse modelo conceptual apresentado por Hagedorn (2000 22 apud MACHADO et al., 2011) é composto por seis catalisadores: fase da vida, circunstâncias familiares/pessoais, categoria profissional, nova instituição, percepção de justiça e estado emocional e três tipos de mediadores: a) realização, reconhecimento, trabalho em si mesmo, responsabilidade, progresso profissional, remuneração; b) gênero, etnia, tipo de instituição, disciplina/área acadêmica; c) relações, qualidade dos estudantes, gestão, ambiente/cultura institucional.

Diante desses modelos diferentes, mas, complementares, é importante ressaltar que a tarefa da gestão não é motivar os indivíduos - mesmo porque isso não é possível, visto que a motivação é um processo intrínseco e nasce no interior de cada um. O que pode ser feito é criar um ambiente desafiador e motivador, no qual os 
indivíduos possam satisfazer suas necessidades (MORO et al., 2013), influenciando no interesse em participar de atividades profissionais.

\section{Metodologia}

O universo da pesquisa foi construído a partir dos docentes doutores das quatro instituições públicas de ensino do Estado de Goiás: Instituto Federal Goiano (IFGoiano), Instituto Federal de Goiás (IFG), Universidade Estadual de Goiás (UEG) e Universidade Federal de Goiás (UFG).

Para se chegar a esse corpus de análise, a primeira etapa da pesquisa foi constituída pela análise de todos os professores doutores que faziam parte do quadro das quatro universidades públicas do estado de Goiás (IFGoiano, IFG, UEG e UFG). A coleta dos dados funcionais dos professores foi realizada a partir do contato com as respectivas Instituições de Ensino - IEs, correspondendo à situação de outubro de 2012. Consequentemente, os dados de produção científica dos pesquisadores correspondem àqueles que possuíam o título de doutor naquela data.

A produção desses pesquisadores foi levantada por meio de pesquisa do Currículo Lattes de cada pesquisador no mês de março de 2013. Posteriormente, foram selecionados os professores/pesquisadores que publicaram ao menos um artigo científico em um período de cinco anos (2009 a 2014).

Dentro desse conjunto levantaram-se aqueles que não estavam credenciados em programas de pós-graduação. O levantamento foi realizado por meio dos dados disponíveis sobre os programas na Capes e complementados com informações disponíveis nas páginas da web dos próprios programas de pós-graduação verificadas nos meses de março e abril de 2014.

A partir dos procedimentos adotados, chegou-se ao número de 578 professores/pesquisadores que reuniam as características desejadas. Para esses professores, foram enviados questionários para identificar aspectos ou fatores do que se buscava estudar.

O questionário foi elaborado utilizando-se os princípios de Herzberg (1966 23 apud MACHADO et al., 2011) sendo aplicado no modelo de Satisfação de Nyquist, Hitchcock e Teherani (2000²4 apud MACHADO et al., 2011), utilizando também dos conceitos apresentados por Hagedon $(2000)^{25}$ sistematizados por Machado et al. 
(2011). Além disso, buscou-se levantar, na literatura, características e possíveis fatores que poderiam influenciar na decisão de participar ou não de programas de pósgraduação. Esse instrumento de coleta de dados foi elaborado utilizando a escala de Likert para compreender os níveis de influência, sendo: Influencia totalmente (5); Influencia fortemente (4); Influencia moderadamente (3); Influencia fracamente (2); Não influencia (1).

Foram elaboradas 22 questões fechadas e uma aberta contemplando os fatores descritos no Quadro 1. 
Revista da Faculdade de Biblioteconomia e Comunicação da UFRGS v. 21, n. 1 - Jan./Abr. 2015

Quadro 1 - Fatores organizacionais, fatores relacionados ao trabalho e fatores pessoais contemplados nas questões

\begin{tabular}{|c|c|c|}
\hline Organizacionais & Trabalho & Pessoais \\
\hline Problemas relacionados a relações pessoais & $\begin{array}{l}\text { Precária política de pós-graduação do } \\
\text { estado de Goiás }\end{array}$ & $\begin{array}{l}\text { Interesse pelas atividades de pesquisa, } \\
\text { orientação, publicação, etc. }\end{array}$ \\
\hline $\begin{array}{l}\text { Discordância com o sistema de avaliação } \\
\text { da Capes }\end{array}$ & $\begin{array}{l}\text { Distância geográfica do programa de } \\
\text { interesse }\end{array}$ & Responsabilidade social e profissional \\
\hline $\begin{array}{l}\text { Ausência de políticas da instituição de } \\
\text { ensino }\end{array}$ & Falta de remuneração & Reconhecimento social \\
\hline $\begin{array}{l}\text { Dificuldade de adaptação com a cultura } \\
\text { institucional }\end{array}$ & $\begin{array}{l}\text { Falta de qualidade da infraestrutura } \\
\text { (biblioteca, laboratórios, etc.) }\end{array}$ & Possibilidade de captação de recursos \\
\hline $\begin{array}{l}\text { Inexistência de linhas de pesquisa de meu } \\
\text { interesse }\end{array}$ & Sobrecarga de trabalho atual & Realização pessoal \\
\hline $\begin{array}{l}\text { Dificuldade de atingir os critérios dos } \\
\text { programas de credenciamento dos } \\
\text { programas de Pós-Graduação }\end{array}$ & \multirow[t]{4}{*}{ Inexistência de programas de interesse } & $\begin{array}{l}\text { Maior liberdade de pesquisa } \\
\text { desenvolvimento acadêmico }\end{array}$ \\
\hline \multirow{3}{*}{ Escassez de recursos para pesquisa } & & Dificuldades relacionadas à família \\
\hline & & Dificuldades relacionadas à saúde \\
\hline & & $\begin{array}{l}\text { Desinteresse nas atividades de pesquisa e } \\
\text { pós-graduação }\end{array}$ \\
\hline
\end{tabular}

Fonte: dados da pesquisa.

O questionário foi enviado por e-mail aos 578 professores/pesquisadores no dia 1 de julho de 2014 e o recebimento das respostas ocorreu até o dia 8 de agosto de 2014. Ao final do prazo de recebimento das respostas, foram recebidas 122 respostas válidas (ou seja, obteve-se apenas 21\% de retorno dos questionários).

Constatou-se, também, que 38 e-mails retornaram (não foram recebidos pelos destinatários), 38 docentes informaram que se credenciaram recentemente em programas de pós-graduação e dois aposentaram-se e desligaram-se da instituição. Os demais não deram nenhum retorno e não responderam o questionário.

\section{Resultados e discussões}

Assim, a partir do retorno das respostas do questionário, contatou-se que, quanto ao perfil, $57 \%$ dos respondentes são do sexo masculino e $43 \%$ do sexo feminino, sendo que $81 \%$ possuem entre 20 e 50 anos e $19 \%$ entre 51 e 70 anos. Em relação ao tempo que estão vinculados à instituição, 46\% estão entre 1 e 5 anos, 24\% de 6 a 10 anos, $14 \%$ de 11 a 15 anos, $7 \%$ de 16 a 20 anos, $7 \%$ de 21 a 25 anos e 3\% estão há mais de 36 anos ligados à instituição. Constatou-se também que $29 \%$ dos respondentes já participaram de programas de pós-graduação stricto sensu e 71\%, não.

Um dado importante é que 94\% dos respondentes afirmaram ter interesse em participar de programas de pós-graduação. Da mesma forma, percebe-se que uma 
parcela importante dos respondentes ingressou recentemente na carreira docente em universidades públicas e que, apesar da quantidade significativa de pessoas que ainda não atuaram nesses programas, quase a totalidade tem o interesse em participar, sendo apenas $6 \%$ os que informaram não ter interesse em se credenciar.

Analisado o conjunto de dados, observa-se que os fatores relacionados ao trabalho e os fatores pessoais possuem baixa influência na decisão do pesquisador em não participar de programas de pós-graduação (Gráfico 1) já que nenhum dos respondentes, a partir das médias das respostas, foi categorizado em "Influencia totalmente" ou "Influencia fortemente".

Observando os fatores organizacionais em conjunto, constata-se que esse aspecto influencia mais fortemente a decisão dos professores/pesquisadores em atuar em programas de pós-graduação. Observou-se que fatores organizacionais influenciam fortemente ou totalmente $20 \%$ dos respondentes. Além disso, os fatores organizacionais em conjunto possuem "Influência moderada" em 36\% dos respondentes, se distinguindo em porcentagem de outros fatores que possuem apenas $31 \%$ e $21 \%$ nesta escala em fatores relacionados ao trabalho e fatores pessoais, respectivamente.

Gráfico 1 - Fatores que influenciam na decisão de professores/pesquisadores participarem ou não de programas de pós-graduação

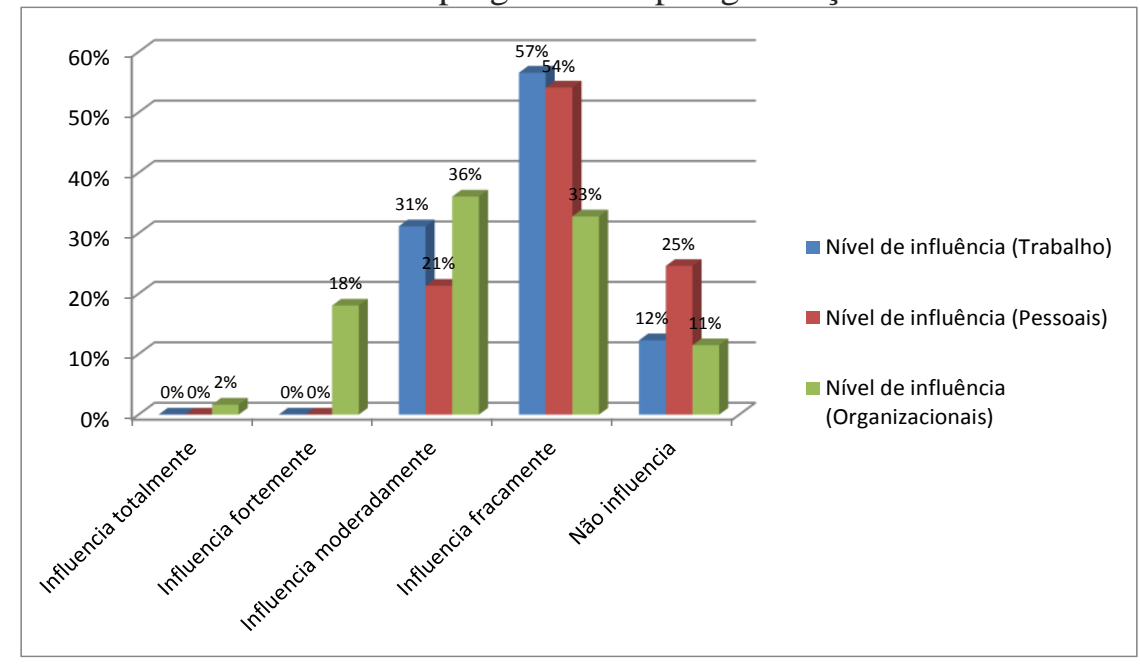

Fonte: dados da pesquisa.

Quando se analisam os fatores pessoais isoladamente, nota-se que nenhum deles demonstra uma larga influência na decisão dos sujeitos analisados. No entanto, ao analisar os fatores relacionados ao trabalho isoladamente, constata-se que um fator Fatores que interferem no (não) credenciamento de pesquisadores em programas de pós- | 166 graduação: um estudo nas universidades públicas em Goiás 
se destaca entre os demais: a "Sobrecarga de trabalho atual". Esse fator alcançou a média de 3,4 na escala de 1 a 5, indicando ser isoladamente, um fator que influencia moderadamente à fortemente a decisão dos professores/pesquisadores em atuar em programas de pós-graduação. Diversos foram os relatos relacionados a acúmulo de responsabilidades e sobrecarga de trabalho, especialmente aquelas relacionadas a demandas administrativas e relacionadas aos cursos de graduação.

A participação em programas de pós-graduação exige do docente qualificação, carga horária, volume/qualidade das publicações e orientações, às quais devem ser somadas a outras várias funções dentro da instituição. Apesar da existência do discurso de forte discordância com o sistema Capes de avaliação, largamente abordado por alguns autores como Gatti et al. (2003), Hortale (2003), Silva (2007), Sguissardi (2006), além da falta de liberdade para a pesquisa abordada por Luz (2005), constatou-se que esse fator por si só não foi apontado como importante na decisão de um professor/pesquisador ingressar ou não em programas de pós-graduação.

No caso dos fatores organizacionais, constata-se que a "Dificuldade de atingir os critérios exigidos pelos programas de pós-graduação" para credenciamento é o principal fator apontado pelos professores/pesquisadores. Esse fator, na escala de 1 a 5 , obteve a mediana 4 , ou seja, ele influencia fortemente o grupo analisado. Vários professores/pesquisadores relatam, de maneira complementar, que os cursos existentes são fechados e que os critérios para credenciamento são fortemente políticos e/ou pouco objetivos. Confirmando essa tendência, observou-se que vários foram os relatos de dificuldades de relacionamento interpessoal.

Finalmente, outro fator organizacional que merece ser destacado refere-se ao fator "Ausência de políticas da instituição de ensino". Esse fator atingiu a mediana 3 para o grupo analisado (Influencia moderadamente). Analisando-se os dados qualitativos, constata-se que os relatos referentes à ausência de políticas incluem aspectos relacionados à exigência de produtividade sem infraestrutura adequada, falta de políticas institucionais e governamentais que deem apoio ao desenvolvimento das pesquisas, falta de infraestrutura física e de recursos humanos, burocracia estatal, dentre outros. 


\section{Conclusão}

O corpo docente é um dos principais componentes para que programas de pósgraduação stricto sensu possam realizar pesquisas e assim estimular o desenvolvimento de conhecimentos para contribuir com a resolução dos problemas da sociedade nos diversos campos do conhecimento.

No entanto, para que o docente/pesquisador credencie-se em programas de pós-graduação é necessário, além do título de doutor e produtividade, que estejam estimulados a atuar ou a participar, ou seja, há outros fatores que podem influenciar na sua decisão de participar ou não de programas de pós-graduação stricto sensu.

A presente pesquisa, ao receber respostas do total de 122 docentes (21\%), traz dados relevantes e significativos tanto qualitativos quanto quantitativos para que se compreenda o fenômeno estudado. Diante dos resultados da presente pesquisa, conclui-se que a maioria dos docentes e pesquisadores tem o interesse em se credenciar na pós-graduação stricto sensu, e encontram-se relativamente motivados, no entanto, insatisfeitos ou desestimulados devido a diversos fatores que, combinados, afetam a sua decisão.

Destaca-se que os fatores estudados, isoladamente, não interferem significativamente na decisão dos pesquisadores de se credenciar ou não de programas de pós-graduação. Nem mesmo fatores que se pressupunha importantes, como o sistema Capes de avaliação e as consequentes críticas ao produtivismo ou distanciamento geográfico entre o professor/pesquisador e programas de pósgraduação, podem, isoladamente, ser considerados fatores relevantes.

\section{Referências}

BALBACHEVSKY, E. A pós-graduação no Brasil: novos desafios para uma política bem-sucedida. In: BROCK. C.; SCHWARTZMAN, S. Os desafios da educação no Brasil. Rio de Janeiro: Nova Fronteira, 2005. p. 275-304. 
BERGAMINI, C. W. Psicologia aplicada à administração de empresas: psicologia do comportamento organizacional. 4. ed. São Paulo: Atlas, 2011.

BRASIL. Portaria n ${ }^{\circ}$ 1, de 4 de janeiro de 2012, Define, para efeitos da avaliação, realizada pela CAPES, a atuação nos programas e cursos de pós-graduação das diferentes categorias de docentes. Diário oficial da União, [Brasília, DF], n. 4, p. 27, 5 jan., 2012.

BRASIL. Portaria ${ }^{\circ}$ 193, de 4 de outubro de 2011, Fixa normas e procedimentos para a apresentação e avaliação de propostas de cursos novos de mestrado e doutorado. Diário Oficial da União, [Brasília, DF], n. 200, p. 14.18 out., 2011. Seção 1.

CABRAL NETO, A.; CASTRO, A. M. D. A. A expansão da pós-graduação em cenários de globalização: recortes da situação brasileira. Inter-Ação, Goiânia, v. 38, n. 2, p. 339-362, mai./ago. 2013.

CASSANDRE, M. P. A saúde de docentes de pós-graduação em universidades públicas: os danos causados pelas imposições do processo avaliativo. Revista Malestar e Subjetividade, Fortaleza, v. 11, n. 2, p. 779-816, jun. 2011.

COORDENAÇÃO DE APERFEIÇOAMENTO DE PESSOAL DE NÍVEL SUPERIOR (CAPES). Avaliação. Disponível em:

<http://www.capes.gov.br/avaliacao >. Acesso em: 15 maio 2014.

COORDENAÇÃO DE APERFEIÇOAMENTO DE PESSOAL DE NÍVEL SUPERIOR (CAPES). GEOCAPES dados estatísticos. Disponível em: <http://geocapes.capes.gov.br/geocapesds/\#>. Acesso em: 15 set. 2013.

DANTAS, F. Responsabilidade social e pós-graduação no Brasil: ideias para (avali)ação. Revista Brasileira de Pós-graduação, Brasília, v. 1, n. 2, p. 141-159, nov. 2004.

GATTI, B. et al. Documento: o modelo de avaliação da CAPES. Revista Brasileira de Educação, Rio de Janeiro, n. 22, jan./abr. 2003.

HORTALE, V. A. Modelo de avaliação CAPES: desejável e necessário, porém, incompleto. Cadernos de Saúde Pública, Rio de Janeiro, v. 6, n.19, p.1837-1840, nov./dez. 2003.

LUZ, M. T. Prometeu acorrentado: análise sociológica da categoria produtividade e as condições atuais da vida acadêmica. Physis: Revista de Saúde Coletiva, Rio de Janeiro, v. 1, n. 15, p. 39- 57, 2005.

MACCARI, E. A.; LIMA, M. C; RICCIO, E. L. Uso do sistema de avaliação da CAPES por programas de pós-graduação em administração no Brasil. Revista de Ciências da Administração, Florianópolis, v. 11, n. 25, p. 68-96, set./dez. 2009. 
MACHADO, M. L. et al. Uma análise da satisfação e da motivação dos docentes no ensino superior Português. Revista Lusófona de Educação, Lisboa, n. 17, p. 167$181,2011$.

MORO, A. B. et al. Fatores motivacionais e higiênicos considerados relevantes na visão dos docentes e discentes de programas de pós-graduação de uma instituição publica federal. Sociais e Humanas, Santa Maria, v. 26, n. 3, p. 608-621, set./dez. 2013.

RIZZATTI, G. Categorias de análise de clima organizacional em universidades federais brasileiras. 2002. $307 \mathrm{f}$. Tese (Doutorado em Engenharia de Produção) Programa de Pós-graduação em Engenharia de Produção, Universidade Federal de Santa Catarina, Florianópolis, 2002.

SGUISSARDI, V. A avaliação defensiva no "modelo CAPES de avaliação" - É possível conciliar avaliação educativa com processos de regulação e controle do Estado? Perspectiva, Florianópolis, v. 14, n. 1, p. 49-88, jan./jun. 2006.

SILVA, A. L. Pós-graduação e CAPES. Revista do Colégio Brasileiro de Cirurgiões, Rio de Janeiro, v. 34, n. 6, p. 360, nov./dez. 2007.

SIMÕES, T. M. S. E. Gerenciando a qualidade da formação na pós-graduação: um estudo de caso no MBA de gerência empresarial e negócios. 2003. Trabalho de Conclusão de Curso (Especialização em Gerência Empresarial e Negócios Universidade de Taubaté, Taubaté, 2003.

\title{
Factors that (do not) affect the accreditation of researchers in graduate programs: a study in public universities of Goiás
}

\begin{abstract}
Postgraduate stricto sensu programs are important for the instruction of researchers, as for the production and dissemination of knowledge and development of technologies. This paper aims to raise the factors that lead researchers to accredit themselves (or not) in such programs, even if they meet with the certain conditions to make it. The methodology used consisted in a questionnaire made to 578 teachers of public institutions of higher education in the state of Goiás (UFG, UEG, and IFGoiano IFGoiás) who had at least one scientific article published in the last five years (2009 to 2014). The total of 122 professors (21\%) answered the questionnaire. It was observed that $94 \%$ of the respondents are interested in participating in post-graduate studies programs. What most influenced the researches in not accreditation in postgraduate programs were organizational factors, however, the factors related to work, the organization of the group combined with personal problems demonstrate a large influence on that decision as well.
\end{abstract}

Fatores que interferem no (não) credenciamento de pesquisadores em programas de pós-

graduação: um estudo nas universidades públicas em Goiás

Itala Moreira Alves, João de Melo Maricato e Dalton Lopes Martins 
Keywords: Graduate school. Lecturer. Organizational behavior. Goias. Public universities.

Recebido: 09/09/2014

Aceito: 20/02/2015

\footnotetext{
${ }^{1}$ HAMBURGER, Ernest. Para quê pós-graduação? In: ANDRADE, Manoel de et al. Encontros com a civilização brasileira. Rio de Janeiro: Civilização Brasileira, 1980. p. 81-93.

${ }^{2}$ LUZ, M. T. Natural, racional, social: razão médica e racionalidade científica moderna. São Paulo: Hucitec, 2004.

${ }^{3}$ LEVY-LEBOYER, Claude. Psychologie des organisations. Paris: Presses Universitaires de France, 1974.

${ }^{4}$ LATHAM, G. P.; ERNST, C. T. (2006). Keys to motivating tomorrows workforce. Human

Resource Management Review, v. 16, n. 2, p. 181-198, 2006.

${ }^{5}$ VALLERAND, R. J. et al. The Academic Motivation Scale: a Measure of Intrinsic, Extrinsic and Amotivation in Education. Educational and Psychological Measurement, v. 52, 1003-1017, 1992.

${ }^{6}$ BLACKBURN, R. T.; LAWRENCE, J. H. Faculty at work: motivation, expectation, satisfaction. Baltimore and London: Johns Hopkins, 1995.

${ }^{7}$ MASLOW, A. Motivation and personality. 2. ed. N.Y.: Harper \& Row, 1970.

${ }^{8}$ ALDERFER, C. Existence, relatedness, and growth: human needs in organizational settings. New York: Free Press, 1972.

${ }^{9}$ HERZBERG, F. Work and the nature of man. New York: Thomas Y. Crowell Publishers, 1966.

${ }^{10}$ VROOM, V. H. Work and motivation. Oxford, England: Wiley, 1964.

${ }^{11}$ ADAMS, J. S. Inequity in social exchange. Advances in Experimental Social Psychology, v. 62, p. 335-343, 1965.

${ }^{12}$ QUARSTEIN, V. A.; McAFEE, R. B.; GLASSMAN, M. The situational occurrences theory of job satisfaction. Human Relations, v. 45, n. 8, p. 859-873, 1992.

${ }^{13}$ GLISSON, C. V.; DURICK, M. Predictors of job satisfaction and organizational commitment in human service organizations. Administrative Quarterly, v. 33, n. 1, p. 61-68, 1988.

${ }^{14}$ GOFF, D. G. Job satisfaction of community college academic deans. 178 f. 2004. Dissertation (Doctor in Eductation) - University of South Florida, Florida, 2004.

${ }^{15}$ MULLINS, L. Management and organizational behavior. 5. ed. London: Financial Times/Pittman Publishing, 1999.

${ }^{16}$ NYQUIST, J. G.; HITCHCOCK, M. A.; TEHERANI, A. Faculty Satisfaction in Academic

Medicine. New Directions for Institutional Research, v. 27, n. 1, p. 33-43, 2000.

${ }^{17}$ HAGEDORN, L. S. Conceptualizing Faculty Job Satisfaction: Components, Theories, and

Outcomes. New Directions for Institutional Research, n. 105, v. 27, n. 1, p. 5-20, 2000.

${ }^{18}$ HERZBERG, op cit.

${ }^{19}$ HAGEDORN, ibidem.

${ }^{20}$ NYQUIST; HITCHOK; TEHERANI, ibidem.

${ }^{21}$ HAGEDORN, ibidem.

${ }^{22}$ HAGEDORN, ibidem.

${ }^{23}$ HERZBERG, op cit.

${ }^{24}$ NYQUIST; HITCHOK; TEHERANI, ibidem.

${ }^{25}$ HAGEDON, ibidem.
} 